\title{
The Anticancer Effects of Novel $\alpha$-Bisabolol Derivatives Against Pancreatic Cancer
}

\author{
YOSHIHIKO MURATA ${ }^{1}$, TOSHIO KOKURYO ${ }^{1}$, YUKIHIRO YOKOYAMA ${ }^{1}$, JUNPEI YAMAGUCHI $^{1}$, \\ TOMOHIRO MIWA $^{1}$, MASATOSHI SHIBUYA ${ }^{2}$, YOSHIHIKO YAMAMOTO ${ }^{2}$ and MASATO NAGINO ${ }^{1}$ \\ ${ }^{1}$ Division of Surgical Oncology, Department of Surgery, \\ Nagoya University Graduate School of Medicine, Nagoya, Japan; \\ ${ }^{2}$ Department of Basic Medicinal Sciences, \\ Nagoya University Graduate School of Pharmaceutical Sciences, Nagoya, Japan
}

\begin{abstract}
Pancreatic cancer is highly malignant, characterized by aggressive proliferation, invasion, and metastasis. $\alpha$-Bisabolol is an oily sesquiterpene alcohol derived from a variety of plants. We previously demonstrated that $\alpha$-bisabolol is a potential therapeutic agent for pancreatic cancer. The aim of this study was to develop $\alpha$-bisabolol derivatives which are more potent than the parent compound and may be clinically useful against pancreatic cancer. First, 22 derivatives of $\alpha$-bisabolol were designed and synthesized. $\alpha$-Bisabolol derivatives $\mathbf{4}$ and $\mathbf{5}$ had more potent inhibitory effects on the proliferation of pancreatic cancer cells than did $\alpha$-bisabolol. Next, 15 additional $\alpha$-bisabolol derivatives were designed and synthesized based on the structure of $\alpha$-bisabolol derivatives $\mathbf{4}$ and 5. Among them, $\alpha$-bisabolol derivative 5 had the strongest inhibitory effect on proliferation. This novel compound reduced the proliferation of various pancreatic cancer cell lines, such as KLM1, Panc1, and KP4. In addition, the compound induced higher levels of apoptosis in pancreatic cancer cell lines than did $\alpha$-bisabolol. $\alpha$-Bisabolol derivative 5 inhibited xenograft tumor growth and reduced dissemination of pancreatic cancer to peritoneal nodules. The compound strongly suppressed AKT expression in the peritoneal nodules. Reduced AKT expression in peritoneal nodules is consistent with an anticancer effect. These data indicate that $\alpha$-bisabolol derivative 5 effectively prevents the progression of pancreatic cancer via inhibition of AKT. Taken together, the results showed that this compound has attractive therapeutic properties as a novel anticancer drug for pancreatic cancer.
\end{abstract}

Correspondence to Toshio Kokuryo, Division of Surgical Oncology, Nagoya University Graduate School of Medicine, 65 Tsurumai-cho, Showa-ku, Nagoya 466-8550, Japan. Tel: +81 527442222, Fax: +81 527442230, e-mail: kokuryoh@med.nagoya-u.ac.jp

Key Words: $\alpha$-Bisabolol derivatives, AKT, pancreas cancer, peritoneal dissemination, apoptosis.
Pancreatic cancer is highly malignant and characterized by aggressive proliferation, invasion and metastasis (1). Although chemotherapy and radiotherapy have improved the prognosis of patients with pancreatic cancer, the impact of these therapies remains unsatisfactory (2). Therefore, the development of novel treatments for advanced pancreatic cancer is needed.

$\alpha$-Bisabolol is an oily sesquiterpene alcohol derived from a variety of plants (3). $\alpha$-Bisabolol inhibits growth and induces apoptosis in several malignancies, including glioblastoma, acute leukemia, and pancreatic, prostatic, breast and liver cancer (3-6). We previously reported that $\alpha$-bisabolol inhibits proliferation, invasiveness and motility of pancreatic cancer cells in vitro and in vivo (7, $8)$.

AKT is a serine/threonine kinase that is frequently activated and promotes resistance to apoptosis and cell growth in several cancer types $(9,10)$. In a previous study, we found that $\alpha$-bisabolol inhibits AKT activation, as well as the expression of its upstream signaling components, such as phosphoinositide-3-kinase (PI3K), phosphoinositidedependent kinase-1 (PDK1), and mechanistic target of rapamycin complex 2 (mTORC2), in pancreatic cancer (7). Based on these results, we hypothesized that AKT may be a key regulator of the anticancer effects of $\alpha$-bisabolol.

In the current study, we aimed to develop $\alpha$-bisabolol derivatives, that are more potent than the parent compound and may be clinically useful against pancreatic cancer. The effects of $\alpha$-bisabolol derivatives on AKT signaling in pancreatic cancer cell lines were investigated using both in vitro and in vivo analyses.

\section{Materials and Methods}

Materials. $\alpha$-Bisabolol was purchased from Sigma-Aldrich (St. Louis, MO, USA), and anti- $\beta$-actin and anti-AKT antibodies were obtained from Cell Signaling Technology (Danvers, MA, USA). 
Preparation of $\alpha$-bisabolol derivatives. $\alpha$-Bisabolol derivatives were designed and synthesized at the Department of Basic Medical Sciences and Nagoya University Graduate School of Pharmaceutical Sciences. $\alpha$-Bisabolol derivatives $\mathbf{3}, \mathbf{4}$ and $\mathbf{5}$ were synthesized via acetylation of $\alpha$-bisabolol (Figure 1a).

Improved preparation of $\alpha$-bisabolol derivatives 4 and $\mathbf{5} . \mathrm{NaOAc}$ (713 $\mathrm{mg}, 8.7 \mathrm{mmol})$ in tetrahydrofuran (THF) $(2.9 \mathrm{ml})$ was added to a mixture of $\alpha$-bisabolol $(967 \mathrm{mg}, 4.35 \mathrm{mmol}$ ) and 2,2,6trimethyl-4H-1,3-dioxin-4-one $(1.42 \mathrm{~g}, 10 \mathrm{mmol})$ at room temperature (11) (Figure 1b). The reaction mixture was heated at $90^{\circ} \mathrm{C}$ for $18 \mathrm{~h}$ and cooled to room temperature. Then the mixture was diluted with $\mathrm{Et}_{2} \mathrm{O}$, quenched with water and extracted with $\mathrm{Et}_{2} \mathrm{O}$. The organic layer was washed with brine, dried over $\mathrm{MgSO}_{4}$ and concentrated under reduced pressure. The crude mixture was purified with silica-gel column chromatography (hexane/AcOEt= 10:1) to yield $\beta$-keto ester $28(1.25 \mathrm{~g}, 94 \%)$ as a colorless oil. $\mathrm{Ac}_{2} \mathrm{O}$ (2.4 ml, $25.4 \mathrm{mmol}), 4$-( $N, N$-dimethylamino)-pyridine (DMAP) $(153 \mathrm{mg}, 1.25 \mathrm{mmol})$, and $\mathrm{Et} 3 \mathrm{~N}(7.0 \mathrm{ml}, 50.2 \mathrm{mmol})$ were added and stirred at room temperature for $4.5 \mathrm{~h}$. The reaction mixture was quenched with $\mathrm{H}_{2} \mathrm{O}(5 \mathrm{ml})$ and extracted with $\mathrm{Et}_{2} \mathrm{O}$. The organic layer was washed with brine, dried over $\mathrm{MgSO}_{4}$ and concentrated under reduced pressure. The crude mixture was purified with silica gel column chromatography (hexane/AcOEt $=20: 1$ ) to yield acetate $4(1.12 \mathrm{~g}, 54 \%)$ and 5 (455 $\mathrm{mg}, 22 \%)$.

Derivative 4 was characterized as a colorless oil; $[\alpha]_{D}^{23-18.6(c}$ $\left.1.09, \mathrm{CHCl}_{3}\right) ;{ }^{1} \mathrm{H}$ nuclear magnetic resonance (NMR) $(400 \mathrm{MHz}$, $\mathrm{CDCl} 3): \delta 5.61(\mathrm{~s}, 1 \mathrm{H}), 5.34(\mathrm{br} \mathrm{s}, 1 \mathrm{H}), 5.12-5.04(\mathrm{~m}, 1 \mathrm{H}), 2.30(\mathrm{~s}$, $3 \mathrm{H}), 2.16(\mathrm{~s}, 3 \mathrm{H}), 2.27-2.10(\mathrm{~m}, 1 \mathrm{H}), 2.08-1.74(\mathrm{~m}, 9 \mathrm{H}), 1.66(\mathrm{~s}$, $3 \mathrm{H}), 1.63(\mathrm{~s}, 3 \mathrm{H}), 1.58(\mathrm{~s}, 3 \mathrm{H}), 1.42(\mathrm{~s}, 3 \mathrm{H}), 1.38-1.22(\mathrm{~m}, 1 \mathrm{H}) ;{ }^{13} \mathrm{C}$ NMR $\left(100 \mathrm{MHz}, \mathrm{CDCl}_{3}\right): \delta 168.2,165.1,162.8,134.1,131.6$, $124.0,120.2,111.6,87.4,40.4,35.5,30.9,26.3,25.6,23.6,23.3$, $22.0,21.1,20.6,17.8,17.5$. IR (neat): $\bar{v} 1768,1715 \mathrm{~cm}^{-1}$ highresolution/accurate mass (HRMS) (DART): $\mathrm{m} / \mathrm{z}$ calcd for $\mathrm{C}_{17} \mathrm{H}_{28} \mathrm{O}_{2} \cdot \mathrm{NH}_{4}\left[\mathrm{M}+\mathrm{NH}_{4}\right]^{+}:$366.2644, found 366.2637.

Derivative 5 was characterized as a colorless oil; $[\alpha]_{\mathrm{D}}{ }^{23}-12.7$ (c $\left.0.97, \mathrm{CHCl}_{3}\right) ;{ }^{1} \mathrm{H} \mathrm{NMR}\left(400 \mathrm{MHz}, \mathrm{CDCl}_{3}\right): \delta 5.54(\mathrm{~s}, 1 \mathrm{H}), 5.33(\mathrm{br}$ $\mathrm{s}, 1 \mathrm{H}), 5.10-5.02(\mathrm{~m}, 1 \mathrm{H}), 2.21(\mathrm{~s}, 3 \mathrm{H}), 2.26-2.12(\mathrm{~m}, 1 \mathrm{H}), 1.97(\mathrm{~s}$, $3 \mathrm{H}), 2.04-1.72(\mathrm{~m}, 9 \mathrm{H}), 1.66(\mathrm{~s}, 3 \mathrm{H}), 1.63(\mathrm{~s}, 3 \mathrm{H}), 1.58(\mathrm{~s}, 3 \mathrm{H}), 1.37$ (s, 3H), 1.36-1.22 (m, 1H); ${ }^{13} \mathrm{C}$ NMR $\left(100 \mathrm{MHz}, \mathrm{CDCl}_{3}\right)$ : $\delta 167.9$, $162.8,158.6,134.1,131.6,124.0,120.2,109.8,87.1,40.3,35.6$, $30.8,26.3,25.7,23.5,23.3,21.9,21.4,21.0,20.5,17.5$. IR (neat): $\bar{v} 1769,1716 \mathrm{~cm}^{-1}$ HRMS (DART): $\mathrm{m} / \mathrm{z}$ calcd for $\mathrm{C}_{17} \mathrm{H}_{28} \mathrm{O}_{2} \cdot \mathrm{NH}_{4}$ $\left[\mathrm{M}+\mathrm{NH}_{4}\right]^{+}:$366.2644, found 366.2636.

Cell culture. KLM1 and Panc1 human pancreatic cancer cell lines were kindly provided by the Cell Resource Center for Biomedical Research Institute of Development, Aging and Cancer at Tohoku University. KP4 human pancreatic cancer cell line was obtained from Riken BioResource Center (Ibaraki, Japan). KLM1, Panc1, and KP4 cells were maintained in RPMI-1640 medium (Invitrogen Life Technologies, Carlsbad, CA, USA) supplemented with $10 \%$ fetal bovine serum (FBS), $100 \mathrm{U} / \mathrm{ml}$ penicillin, and $100 \mu \mathrm{g} / \mathrm{ml}$ streptomycin. These cell lines were incubated at $37^{\circ} \mathrm{C}$ in a humidified atmosphere containing $5 \% \mathrm{CO}_{2}$.

Morphological analysis. KLM1, Panc1, and KP4 cells $\left(1 \times 10^{5}\right.$ cells/well) were seeded and cultured in six-well plates at $37^{\circ} \mathrm{C}$ in a humidified atmosphere with $5 \% \mathrm{CO}_{2}$. Twenty-four hours later, the medium was removed and replaced with fresh medium containing
$62.5 \mu \mathrm{M}$ of $\alpha$-bisabolol or $\alpha$-bisabolol derivatives; this time point was set as $0 \mathrm{~h}$. After $72 \mathrm{~h}$, the cell morphology was analyzed.

Western blot analysis. Tumor tissues were prepared by lysis in Laemmli sample buffer. Equivalent amounts of cell lysate were separated by electrophoresis on sodium dodecyl sulfate polyacrylamide gels, transferred to polyvinylidene difluoride membranes (Immobilon; Millipore, Billerica, MA, USA), and probed with antibodies against $\beta$-actin and AKT. Signals were detected using an ECL system (GE Healthcare Life Sciences, Buckinghamshire, UK).

WST-1 cell proliferation assay. KLM1 cells were seeded at 2,000 cells/well in 96 -well plates. After incubation overnight at $37^{\circ} \mathrm{C}$, the medium was removed and replaced with fresh medium containing $100 \mu \mathrm{M} \alpha$-bisabolol or $\alpha$-bisabolol derivatives; this time point was set as $0 \mathrm{~h}$. At 24 or $48 \mathrm{~h}, 10 \mu \mathrm{l}$ of WST- 1 solution (Roche, Indianapolis, IN, USA) was added to each well, and the cells were incubated for a further 90 minutes, after which the absorbance of each well was determined at 450 and $630 \mathrm{~nm}$ using a microplate reader.

Bromodeoxyuridine (BrdU) cell proliferation analysis. BrdU assays were performed using a CyxLex Cellular BrdU ELISA kit (CyxLex, Nagano, Japan) according to the manufacturer's instructions. KLM1, Panc1, and KP4 cells were seeded at 3,000 cells/well in 96well plates. After incubation overnight at $37^{\circ} \mathrm{C}$, the medium was removed and replaced with fresh medium containing different concentrations of $\alpha$-bisabolol or $\alpha$-bisabolol derivatives $(62.5 \mu \mathrm{M}$ and $125 \mu \mathrm{M}$ ); this time point was set as $0 \mathrm{~h}$. After $48 \mathrm{~h}, 10 \mu \mathrm{M}$ BrdU was added to each well, and the cells were incubated for further $2 \mathrm{~h}$. The absorbance of each well was then measured at $450 \mathrm{~nm}$ using a microplate reader.

Cell viability assay. Cell death was assessed using the trypan blue dye exclusion test. KLM1, Panc1, and KP4 cells were seeded at a density of $1 \times 10^{5}$ cells/well in 6 -well plates. After the samples were incubated overnight at $37^{\circ} \mathrm{C}$, the medium was removed and replaced with fresh medium containing different concentrations of $\alpha$-bisabolol or $\alpha$-bisabolol derivatives $(62.5 \mu \mathrm{M}$ and $125 \mu \mathrm{M})$; this time point was set as $0 \mathrm{~h}$. After $96 \mathrm{~h}$, the floating and attached cells were collected and stained with $1 \%$ trypan blue. The cell counts were determined using a Countess Automated Cell Counter (Invitrogen Life Technologies, Carlsbad, CA, USA) in two wells per treatment.

Apoptotic analyses. Apoptotic analyses were performed using a MuseTM Annexin V \& Dead Cell kit (Millipore, Darmstadt, Germany) according to the manufacturer's instructions. KLM1, Panc1, and KP4 cells were seeded at $1 \times 10^{5}$ cells/well in 6-well plates. After incubation at $37^{\circ} \mathrm{C}$ for $24 \mathrm{~h}$, the medium was removed and replaced with fresh medium containing $62.5 \mu \mathrm{M}$ of $\alpha$-bisabolol or $\alpha$-bisabolol derivatives; this time point was set as $0 \mathrm{~h}$. After $48 \mathrm{~h}$, the floating and attached cells were collected, and the apoptotic rate was analyzed using a Muse Cell Analyzer (Millipore, Darmstadt, Germany).

Antitumor efficacy in animal models. Male BALB/c nude mice ( 7 weeks old and weighing approximately 20-25 g) were purchased from SLC Japan (Nagoya, Japan) and were housed in a temperature- 

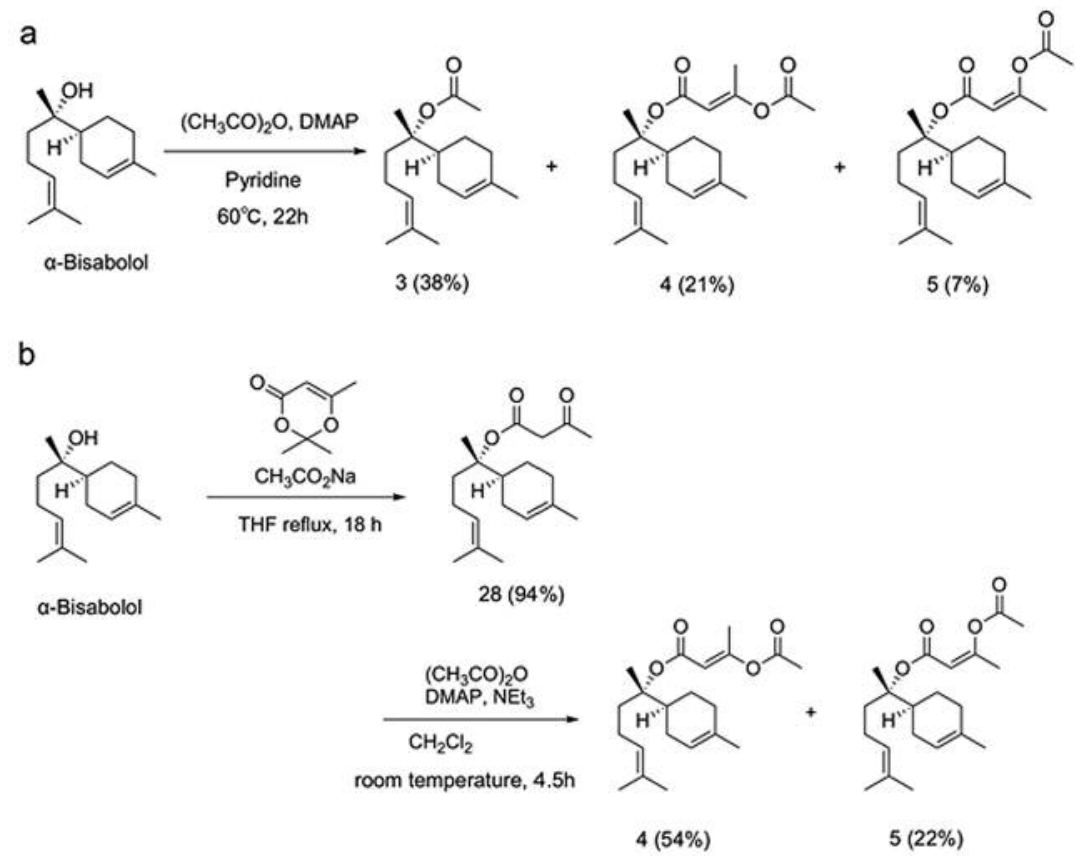

Figure 1. Preparation of $\alpha$-bisabolol derivatives. a: Preparation protocol for $\alpha$-bisabolol derivatives 3,4 and 5 . $b$ : Improved preparation route of $\alpha$-bisabolol derivatives 4 and 5. THF: Tetrahydrofuran; DMAP: 4-(N,N-dimethylamino)-pyridine; $N E t_{3}$ : triethylamine.

and humidity-controlled environment under a $12 \mathrm{~h}$ light-dark cycle. Animals were allowed ad libitum access to water and food. Animal experiments were performed in compliance with the guidelines of the Institute for Laboratory Animal Research of Nagoya University Graduate School of Medicine.

Subcutaneous xenograft model. Mice were implanted with KLM1 cells $\left(1 \times 10^{7}\right.$ cells $\left./ 100 \mu \mathrm{l}\right)$ injected subcutaneously into the femoral area. After 4 days, $\alpha$-bisabolol $(1,000 \mathrm{mg} / \mathrm{kg})$ or $\alpha$-bisabolol derivative $5(1,000 \mathrm{mg} / \mathrm{kg})$ diluted in olive oil (total volume $200 \mu \mathrm{l})$ were administered intragastrically twice a week for 2.5 weeks (for a total of five doses). Intragastric administration of an equal volume of olive oil alone was used as a control. The antitumor efficacy was assessed by determining the tumor volume $\left(\right.$ in $\mathrm{mm}^{3}$ ), which was calculated according to the equation $\left(A \times B^{2}\right) / 2$, where $A$ is the major axis length of the tumor (in $\mathrm{mm}$ ), and B is the minor axis length of the tumor (in $\mathrm{mm}$ ).

Peritoneal xenograft model. KLM1 cells $\left(1 \times 10^{7}\right)$ were injected into the intraperitoneal cavity of the mice. After 4 days, $\alpha$-bisabolol $(1000 \mathrm{mg} / \mathrm{kg})$ or $\alpha$-bisabolol derivative $5(1000 \mathrm{mg} / \mathrm{kg})$ diluted in olive oil (total volume of $200 \mu \mathrm{l}$ ) were administered intragastrically twice a week for 1.5 weeks (for a total of three doses). Intragastric administration of an equal volume of olive oil was used as a control. Two weeks after KLM1 implantation, pancreatic cancer markers carcinoembryonic antigen (CEA) and carbohydrate antigen 19-9 (CA19-9) in the ascitic fluid were measured.

Statistical analysis. Data are presented as the mean \pm SEM. The significance of differences between experimental values was assessed using repeated ANOVA and Bonferroni's method. $p<0.05$ was considered statistically significant.

\section{Results}

Structure-based development of $\alpha$-bisabolol derivatives. Twenty-two $\alpha$-bisabolol derivatives were designed and synthesized as the first set of $\alpha$-bisabolol derivatives. $\alpha$ Bisabolol derivatives $\mathbf{1}, \mathbf{3}, \mathbf{4}, \mathbf{5}, \mathbf{8}, \mathbf{2 1}$ and $\mathbf{2 4}$ had a more potent inhibitory effect on the proliferation of KLM1 cells than did $\alpha$-bisabolol (control) (Figure 2a). Next, 15 additional $\alpha$-bisabolol derivatives were designed and synthesized based on the structure of $\alpha$-bisabolol derivatives 4 and 5 , which constituted the second set of $\alpha$-bisabolol derivatives. Among them, $\alpha$-bisabolol derivative 5 had the strongest inhibitory effect on the proliferation of KLM1 cells (Figure 2b). Therefore, we used $\alpha$-bisabolol derivative 5 for the subsequent analyses.

Inhibitory effect of $\alpha$-bisabolol derivative 5 on the proliferation of pancreatic cancer cell lines. $\alpha$-Bisabolol and $\alpha$-bisabolol derivative 5 at a concentration of $125 \mu \mathrm{M}$ equally inhibited the proliferation of pancreatic cancer cell lines KLM1, Panc1, and KP4 (Figure 3). In contrast, at a lower dose $(62.5 \mu \mathrm{M})$, the growth-inhibitory effect of $\alpha$ bisabolol derivative 5 on these cell lines was greater than 

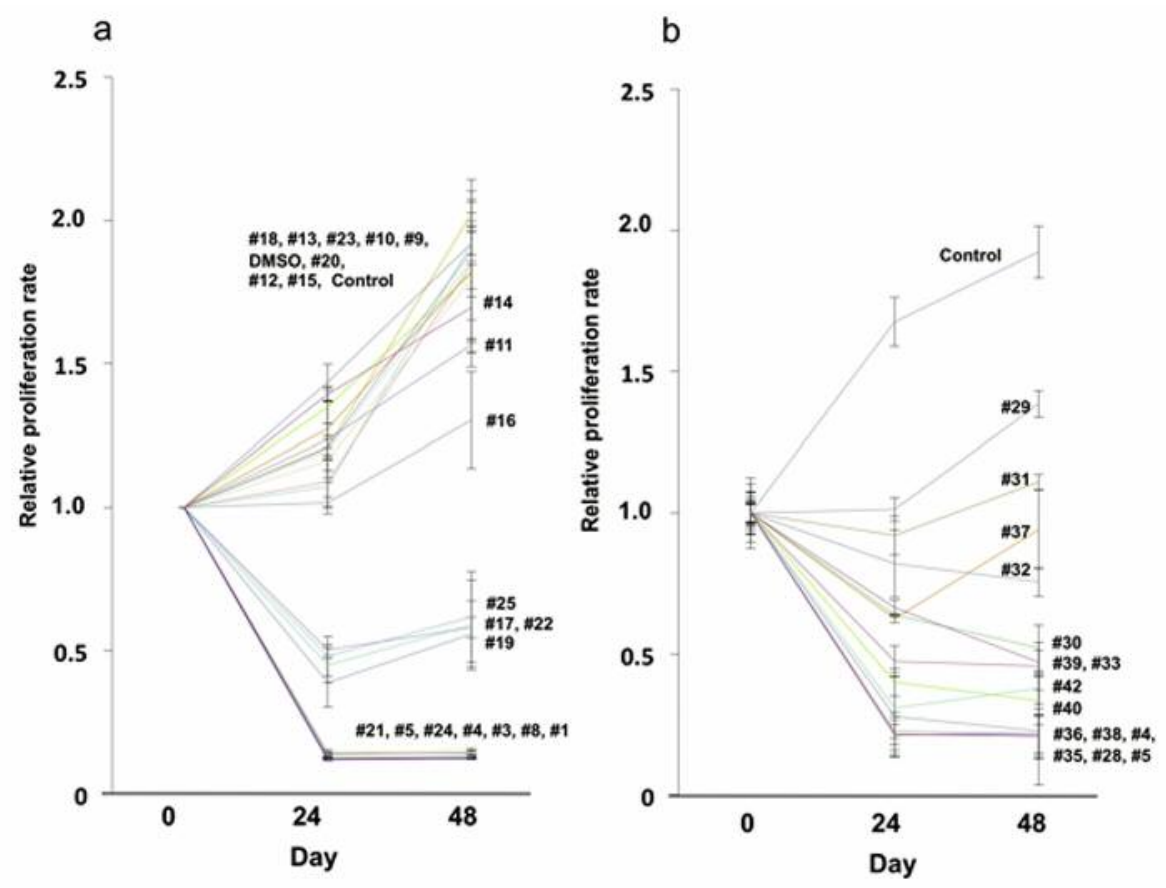

Figure 2. Structure-based development of a-bisabolol derivatives. Cell proliferation was assessed in KLM1 cells using the WST-1 cell proliferation assay. The cells were untreated, treated with $\alpha$-bisabolol, treated with one of 22 first-generation $\alpha$-bisabolol derivatives (numbered from $\mathbf{1}$ to $\mathbf{2 5}$, except 2, 6 and 7) (a) or with 15 second-generation $\alpha$-bisabolol derivatives (numbered from 28 to 42, except 34 and 41) (b) at 100 $\mu M$. The cells were tested for proliferation at 0,24 and $48 \mathrm{~h}$ after administration. The data are shown relative to the zero time point. Each point represents the mean of six replicate wells.

that of $\alpha$-bisabolol. Induction of apoptosis in pancreatic cancer cell lines by $\alpha$-bisabolol derivative $\mathbf{5}$.

$\alpha$-Bisabolol derivative 5 and $\alpha$-bisabolol at concentrations of $125 \mu \mathrm{M}$ and $62.5 \mu \mathrm{M}$ increased cell death in all tested cell lines relative to that of the untreated group (Figure 4a). Compared to $\alpha$-bisabolol, $\alpha$-bisabolol derivative $\mathbf{5}$ induced a notable change in cell morphology, which included the loss of cell membrane asymmetry and attachment (Figure 4b). The percentage of total apoptotic cells following treatment with $\alpha$-bisabolol derivative 5 was greater than that after the treatment with $\alpha$-bisabolol in all tested pancreatic cancer cell lines (Figure 4c).

Antitumor effects of $\alpha$-bisabolol derivative 5 in a subcutaneous xenograft model. The mean tumor volumes 42 days after subcutaneous implantation of KLM1 cells in mice treated with $\alpha$-bisabolol derivative $5(\mathrm{n}=5)$ and in those treated with $\alpha$-bisabolol $(n=5)$ were lower than those in untreated mice $(\mathrm{n}=5)$ (Figure 5a and $\mathrm{b}$ ). In addition, $\alpha$-bisabolol derivative $\mathbf{5}$ suppressed tumor expression of AKT compared with that in the tumors of untreated mice (Figure $5 \mathrm{c}$ ).

Effect of $\alpha$-bisabolol derivative 5 on peritoneal dissemination. Nodules indicative of peritoneal dissemination were identified in untreated $(n=3)$ and $\alpha$-bisabolol-treated mice $(n=3)$ (Figure 6a). In contrast, few nodules were identified in the peritoneal cavity of mice treated with $\alpha$-bisabolol derivative $5(n=3)$. The levels of tumor markers CEA and CA19-9, in the ascitic fluid of the mice treated with $\alpha$-bisabolol derivative 5 were lower than those in the $\alpha$-bisabolol-treated and untreated mice (Figure 6b). Moreover, $\alpha$-bisabolol derivative 5 suppressed AKT expression in the peritoneal nodules (Figure 6c).

\section{Discussion}

$\alpha$-Bisabolol has been shown to exert antitumor, gastricprotective, antimicrobial, antioxidant, and anti-inflammatory effects $(7,8,12)$. In the present study, we synthesized further $\alpha$-bisabolol derivatives and analogs in order to identify a more effective compound than $\alpha$-bisabolol for the treatment of pancreatic cancer. From the first set of $\alpha$-bisabolol derivatives, $\alpha$-bisabolol derivatives $\mathbf{4}$ and $\mathbf{5}$ showed strong inhibitory effects on the proliferation of pancreatic cancer cells. $\alpha$-Bisabolol derivatives $\mathbf{4}$ and $\mathbf{5}$ are byproducts of acetylation of $\alpha$-bisabolol and have the structurally characteristic enol ether of the $\beta$-keto ester moiety, which is formed by condensation of three acyl units. To efficiently prepare high levels of $\alpha$-bisabolol derivatives $\mathbf{4}$ and $\mathbf{5}$, as 

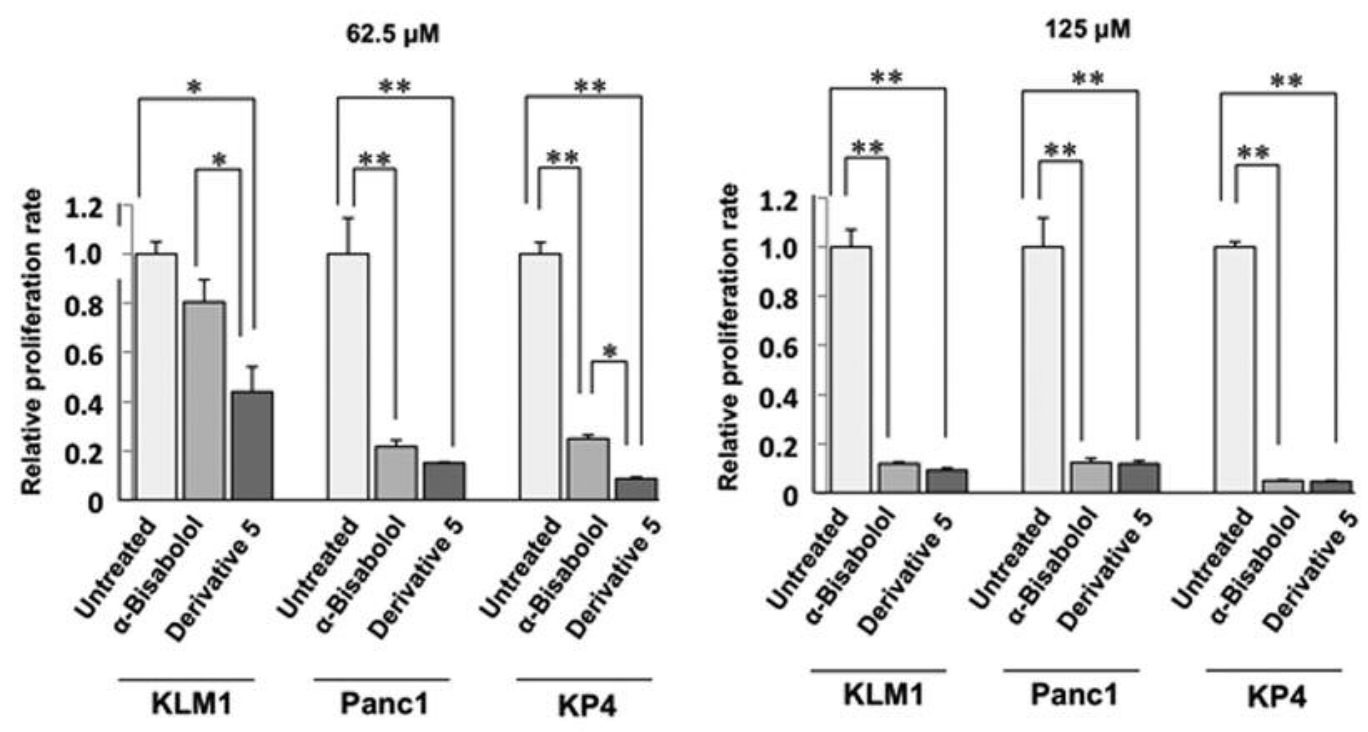

Figure 3. Inhibitory effect of $\alpha$-bisabolol derivative 5 on the proliferation of pancreatic cancer cell lines. Cell proliferation was assessed in KLM1, Pancl and KP4 cells using the bromodeoxyuridine (BrdU) cell proliferation assay. The cells were untreated, treated with $\alpha$-bisabolol or treated with $\alpha$-bisabolol derivative 5 at 62.5 and $125 \mu M$ for $48 \mathrm{~h}$. The graphs show proliferation relative to that of the untreated group. Each bar in the graph represents the mean proliferation for each experimental group \pm SE. Statistically significantly different at $* p<0.05$ and $* * p<0.001$.

well as their analogs, we developed an improved synthetic route, which is shown in Figure 1b. The inhibitory activity of $\alpha$-bisabolol derivatives $\mathbf{4}$ and $\mathbf{5}$ derived via the improved preparation route was re-examined together with 13 newly synthesized analogs. Among these, $\alpha$-bisabolol derivative $\mathbf{5}$ exerted better antiproliferative and tumoricidal efficacies at lower concentrations than those of $\alpha$-bisabolol.

In addition, this novel compound induced greater apoptosis in pancreatic cancer cell lines than did $\alpha$-bisabolol. Apoptosis is characterized by distinct morphological features, including the loss of cell membrane asymmetry and DNA condensation and cleavage $(13,14)$. Several previous reports have indicated that $\alpha$-bisabolol induces apoptosis via the intrinsic pathway through a mechanism involving lipid rafts, BH3-interacting domain death agonist and Fas cell surface death receptor, as well as via mitochondria-related pathways involving p53, nuclear factor-kB and mitochondrial pore permeability $(3,6$, 12, 15). In this study, $\alpha$-bisabolol derivative 5 induced more dramatic morphological changes in pancreatic cancer cells than did $\alpha$-bisabolol. Although we did not investigate the detailed molecular events of apoptosis, the difference in the morphological features after treatment with $\alpha$-bisabolol and $\alpha$-bisabolol derivative 5 indicated a higher potential of $\alpha$ bisabolol derivative $\mathbf{5}$ in inducing apoptosis in pancreatic cancer cells.

Interestingly, the ratio of early apoptotic (annexin Vpositive and PI-negative) and late apoptotic (annexin Vpositive and PI-positive) cells (16) following $\alpha$-bisabolol treatment differed among the pancreatic cancer cell lines. In the KLM1 and Panc1 cell lines, the proportion of late apoptotic cells was much higher than that of early apoptotic cells. In contrast, in the KP4 cell line, the proportions of late apoptotic cells and early apoptotic cells were equivalent. Early apoptotic cells can progress to become late apoptotic cells (17). The observations in this study suggest that the speed of apoptosis induction in response to $\alpha$-bisabolol and to $\alpha$-bisabolol derivative 5 differs among different pancreatic cancer cell lines.

Data from our in vivo experiments revealed that $\alpha$-bisabolol and $\alpha$-bisabolol derivative 5 inhibited xenograft tumor growth and peritoneal dissemination of pancreatic cancer. $\alpha$-Bisabolol derivative 5 strongly reduced the presence of nodules indicative of peritoneal dissemination of pancreatic cancer compared to that of $\alpha$-bisabolol. The inhibitory effects of this novel compound differed between the subcutaneous xenograft models and peritoneal dissemination models. As a subcutaneous xenograft tumor is larger than a nodule, both $\alpha$ bisabolol and $\alpha$-bisabolol derivative $\mathbf{5}$ may have difficulty in reaching the center of the tumor and suppressing tumor growth. In addition, the transitional rate of $\alpha$-bisabolol derivative 5 to the nodules may be superior to that of $\alpha$ bisabolol. Thus, $\alpha$-bisabolol derivative $\mathbf{5}$ has greater therapeutic potential for peritoneal dissemination of pancreatic cancer compared to that of $\alpha$-bisabolol.

Activation of AKT, a serine/threonine kinase, is associated with prognosis of patients with pancreatic cancer 

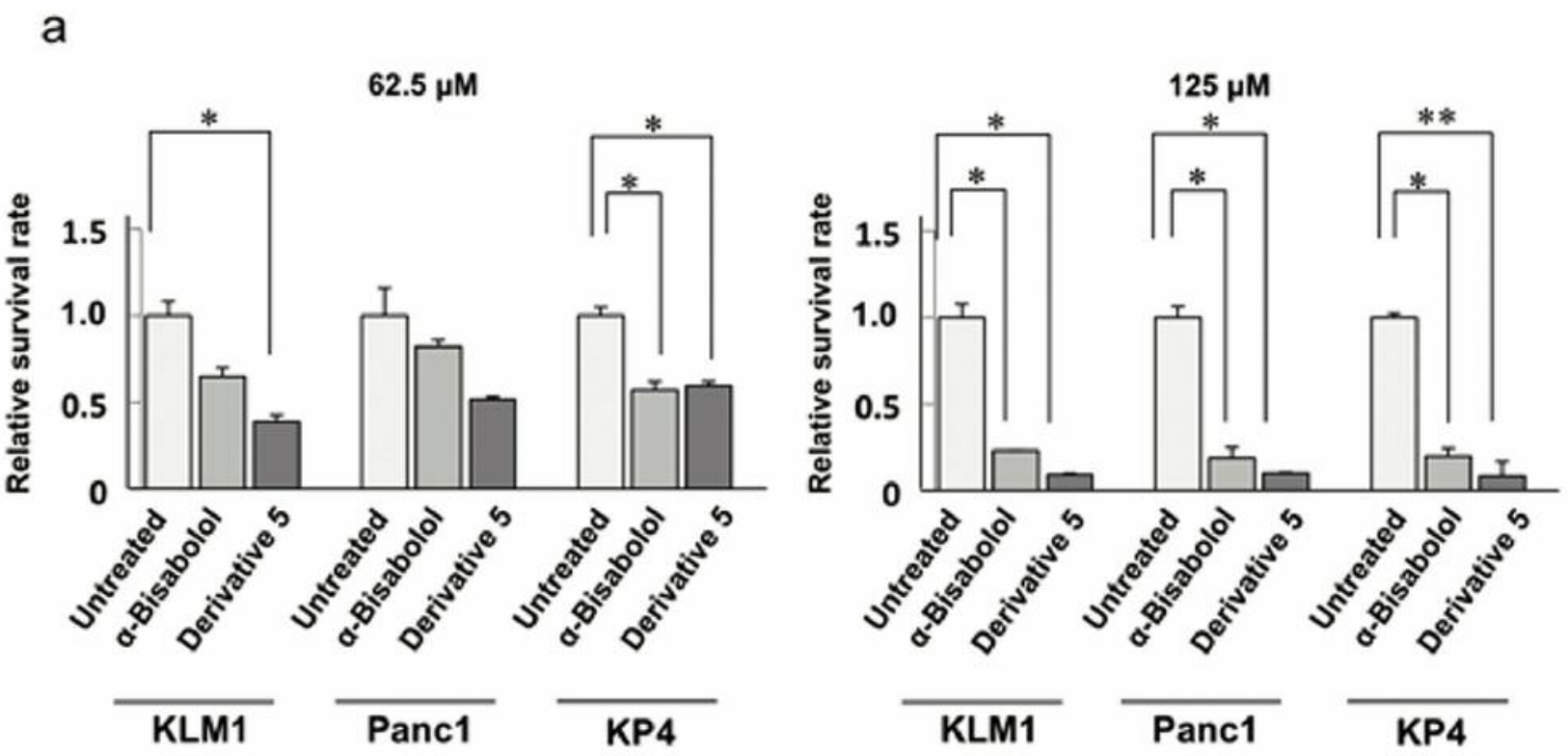

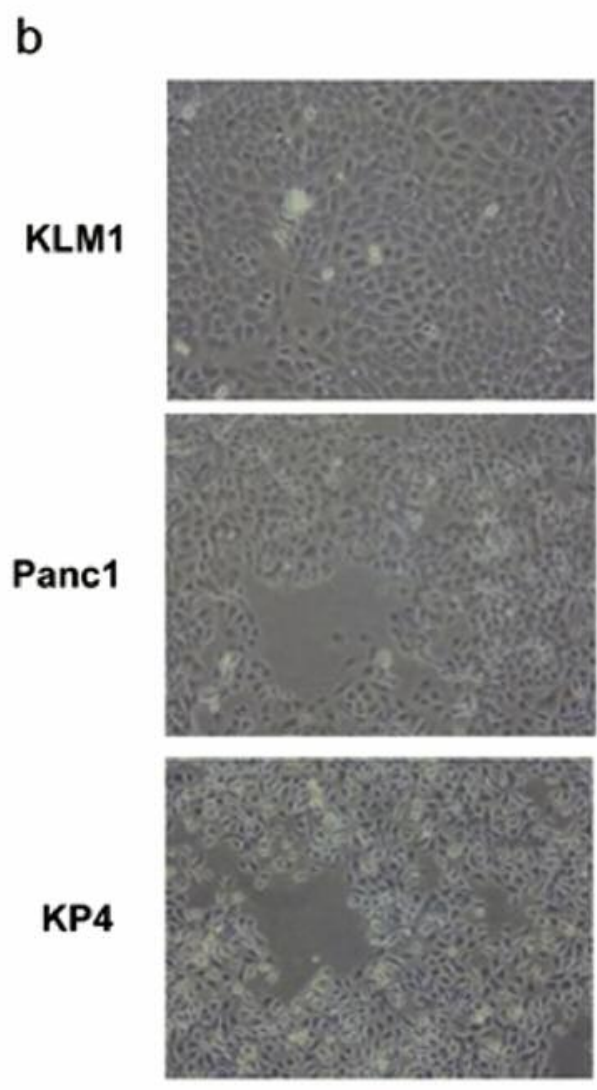

Untreated
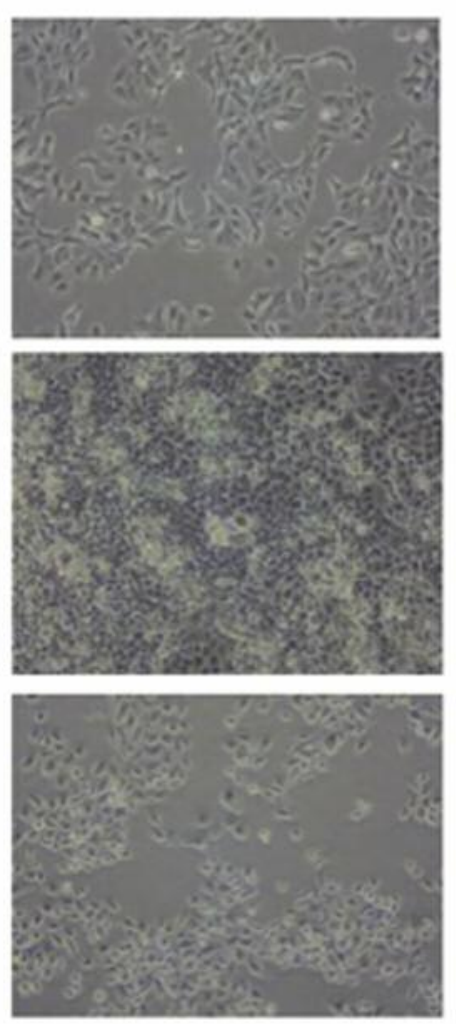

$\alpha-B$ isabolol
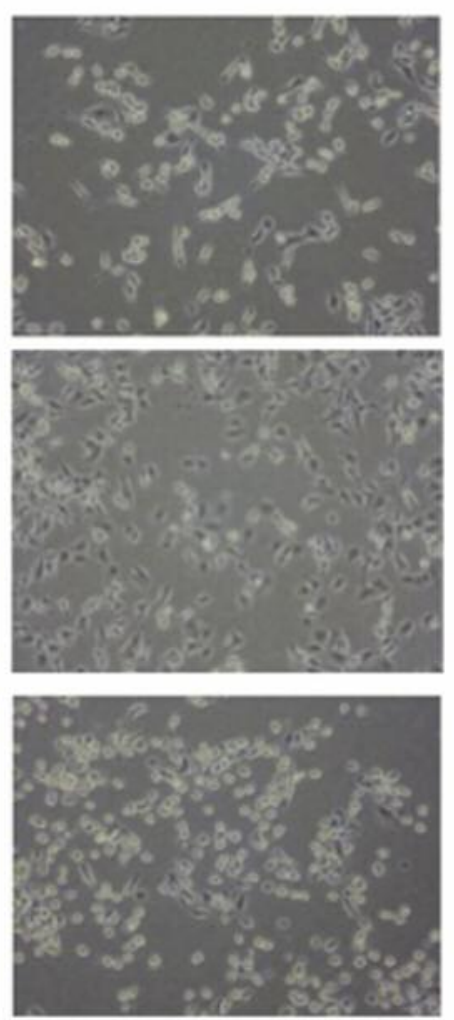

Derivative 5 
C
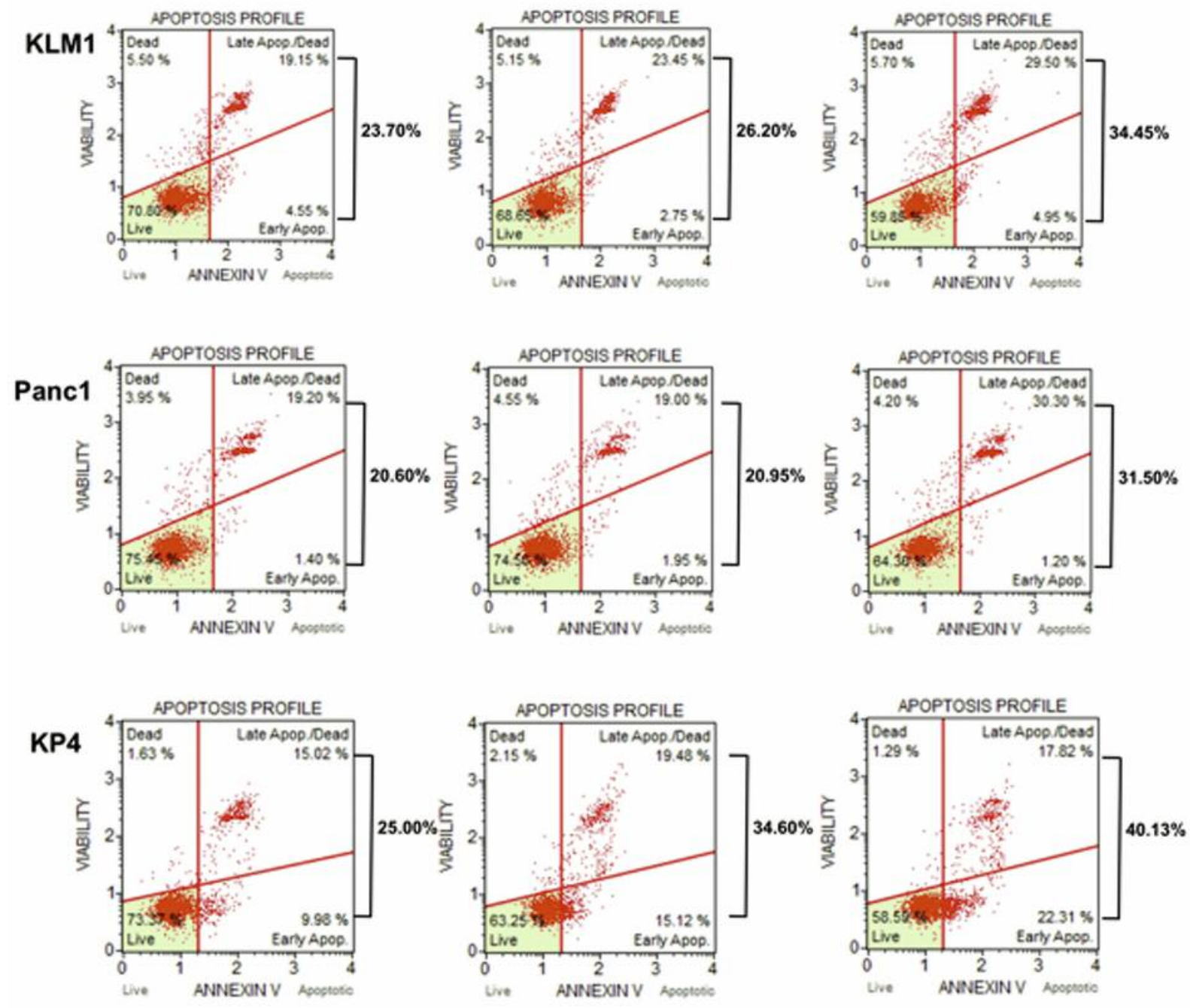

\section{Untreated}

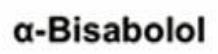

\section{Derivative 5}

Figure 4. Induction of apoptosis in pancreatic cancer cell lines by $\alpha$-bisabolol derivative 5. a: Cell viability was analyzed in KLM1, Panc1 and KP4 cells using the trypan blue dye exclusion test. The cells were untreated, treated with $\alpha$-bisabolol, or treated with $\alpha$-bisabolol derivative 5 at 62.5 and $125 \mu \mathrm{M}$ for $96 \mathrm{~h}$. The graphs show the percentages of live cells relative to the untreated group. Each bar in the graph represents the mean viability of each experimental group \pm SE. Statistically significantly different at $* p<0.05$ and ${ }^{* *} p<0.001$. b: Images depicting cell morphology of KLM1, Panc1 and KP4 cells $48 \mathrm{~h}$ after administration of $\alpha$-bisabolol, and of $\alpha$-bisabolol derivative 5 at $62.5 \mu M$. c: Apoptosis was assessed in KLM1, Pancl and KP4 cells using the Muse ${ }^{T M}$ Annexin V \& Dead Cell Assay kit. The cells were untreated, treated with a-bisabolol, or treated with $\alpha$-bisabolol derivative 5 at $62.5 \mu \mathrm{M}$ for $48 \mathrm{~h}$. Each panel shows the populations of live, dead, early apoptotic and late apoptotic cells.

(18). Therefore, AKT-targeted molecular therapy has become an area of intense research in the development of more effective therapies against pancreatic cancer. $\alpha$ Bisabolol derivative $\mathbf{5}$ strongly suppressed AKT expression in the nodules. Reduced AKT expression in the nodules is consistent with the anticancer effect of the novel compound. These data indicate that $\alpha$-bisabolol derivative $\mathbf{5}$ can effectively prevent the progression of pancreatic cancer via inhibition of AKT.

In summary, $\alpha$-bisabolol derivative 5 has attractive therapeutic properties as a novel anticancer drug for pancreatic cancer. This compound is an AKT inhibitor and a promising therapeutic for advanced pancreatic cancer, particularly with respect to peritoneal dissemination. For 
a

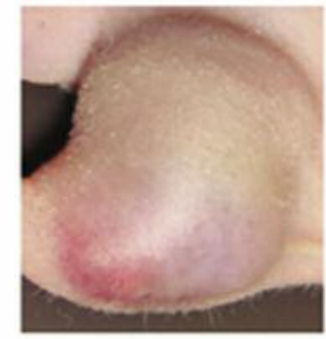

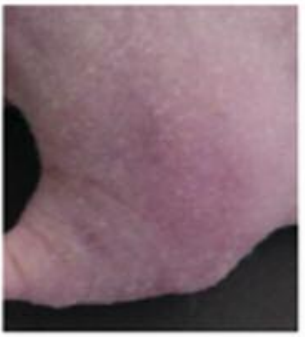

a-Bisabolol

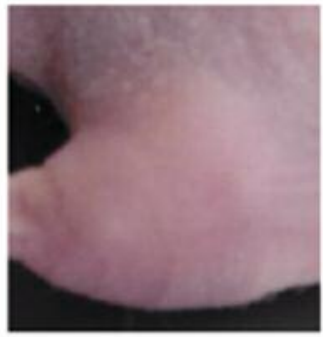

Derivative 5

b

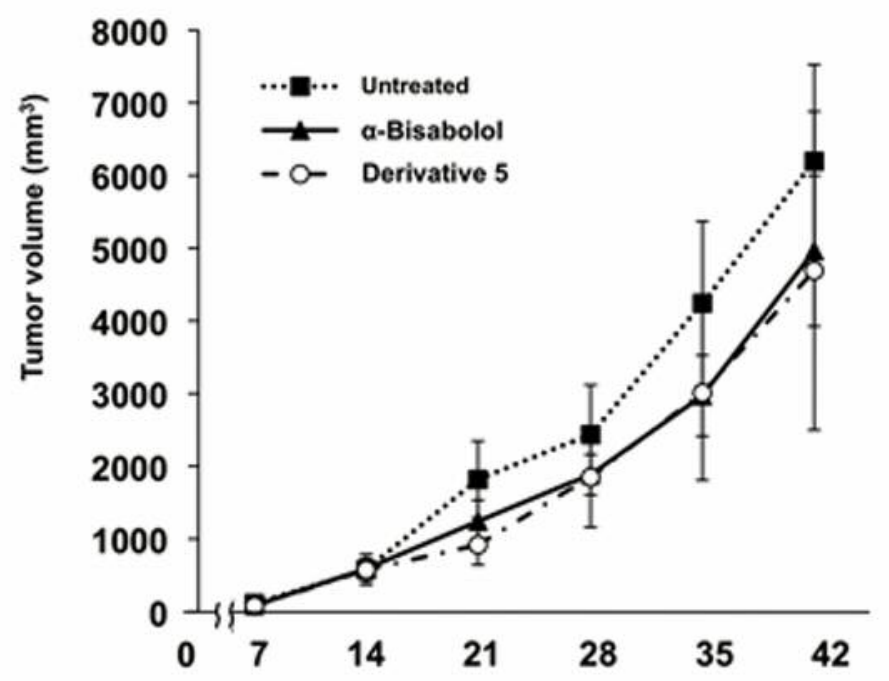

Day

C

AKT

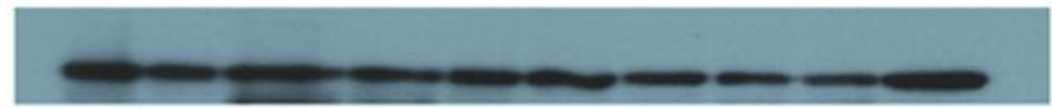

$\beta$-Actin

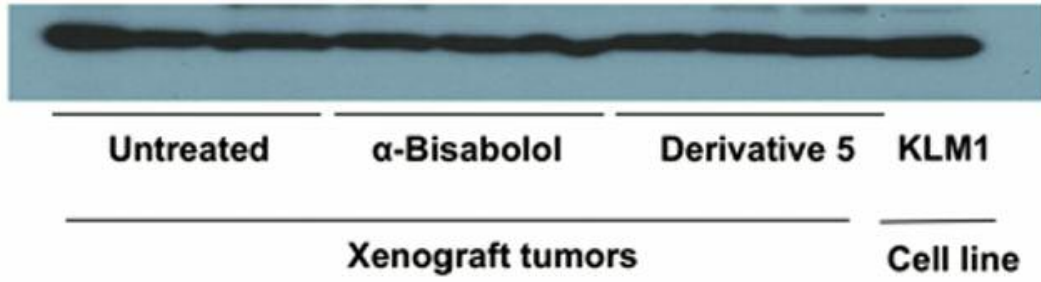

Figure 5. Antitumor effects of $\alpha$-bisabolol derivative 5 in subcutaneous xenograft mouse models. a: Images depicting the KLM1 xenograft tumors excised at the experimental endpoint from mice that were untreated $(n=5)$, treated with $\alpha$-bisabolol $(n=5)$ or treated with $\alpha$-bisabolol derivative 5 $(n=5) . b$ : Graphs showing the volume of KLM xenograft tumors excised from mice that were untreated, treated with $\alpha$-bisabolol, or treated with $\alpha$ bisabolol derivative 5. Each bar in the graph represents the average tumor volume for each experimental group \pm SE. $c$ : AKT expression was assessed by western blot analysis of protein from KLM1 xenograft tumors excised at the experimental endpoint from mice that were untreated, treated with $\alpha$-bisabolol, or treated with $\alpha$-bisabolol derivative 5 . $\beta$-Actin was used as an internal loading control.

clinical application of this compound, further investigations are required to elucidate the detailed anti-cancer mechanism of this novel agent in pancreatic cancer.

\section{Conflicts of Interest}

The Authors have no conflicts of interest. 
a

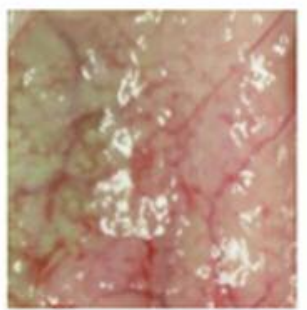

Untreated

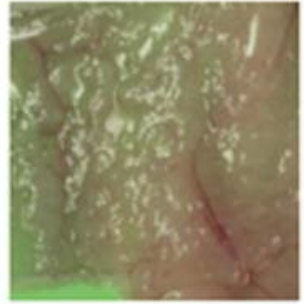

a-Bisabolol

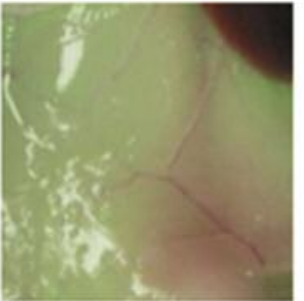

Derivative 5
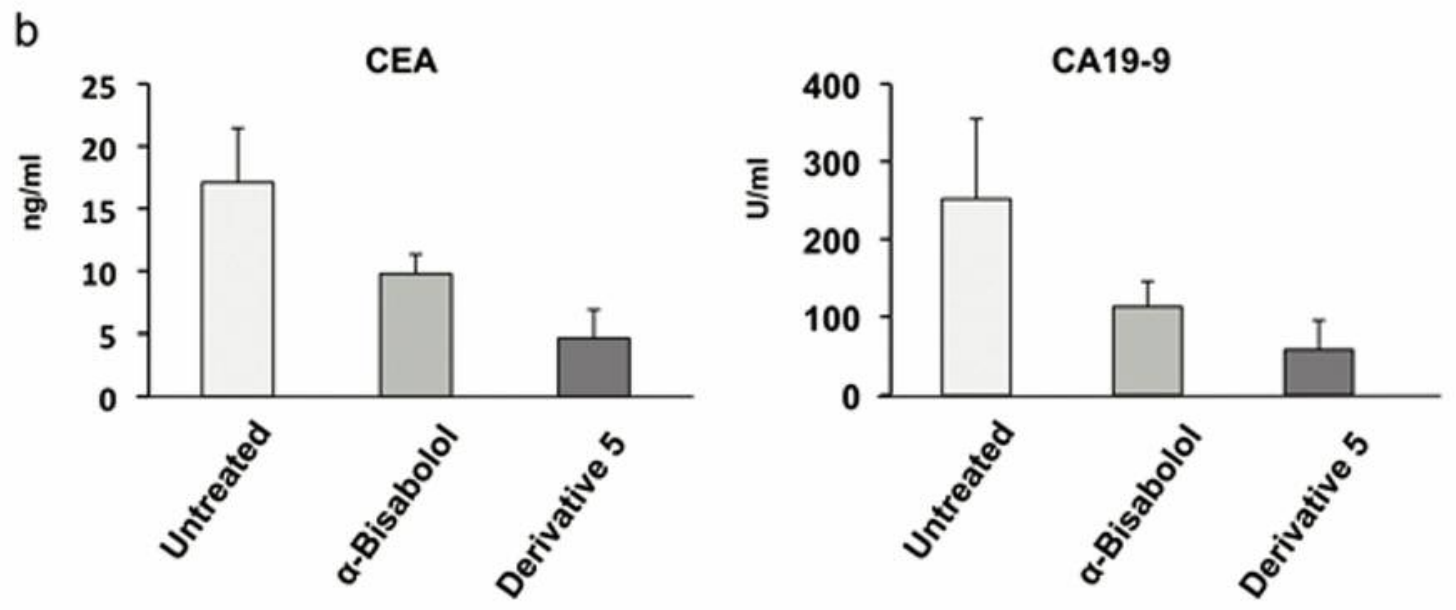

C

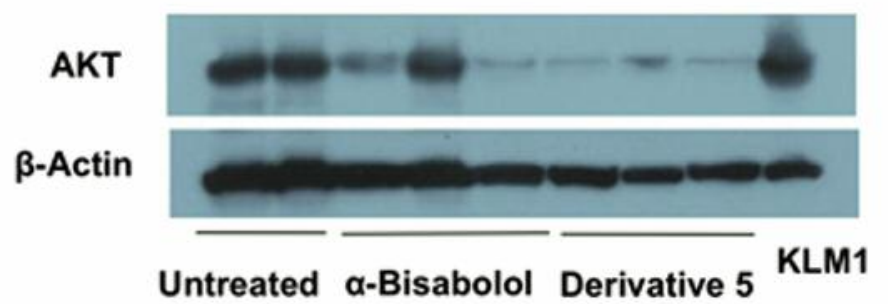

\section{Peritoneal dissemination Cell line}

Figure 6. Effectiveness of $\alpha$-bisabolol derivative 5 for treating peritoneal dissemination in nude mice. a: Images depicting peritoneal dissemination in mice that were untreated $(n=3)$, treated with $\alpha$-bisabolol $(n=3)$, or treated with $\alpha$-bisabolol derivative 5 ( $n=3)$. $b$ : Graphs showing levels of carcinoembryonic antigen (CEA) and carbohydrate antigen 19- 9 (CA19-9) in the ascites of mice that were untreated, treated with $\alpha$-bisabolol, or treated with $\alpha$-bisabolol derivative 5. Each bar represents the average value for each experimental group \pm SE. $c$ : AKT expression was assessed by western blot analysis of cancer cells collected from the ascites at the experimental endpoint in mice that were untreated, treated with $\alpha$-bisabolol, or treated with $\alpha$-bisabolol derivative 5 . $\beta$-Actin was used as an internal loading control.

\section{References}

1 Bardeesy N and DePinho RA: Pancreatic cancer biology and genetics. Nat Rev Cancer 2: 897-909, 2002.

2 Takahashi H, Ohigashi H, Gotoh K, Marubashi S, Yamada T, Murata $\mathrm{M}$, Ioka $\mathrm{T}$, Uehara $\mathrm{H}$, Yano $\mathrm{M}$ and Ishikawa $\mathrm{O}$ : Preoperative gemcitabine-based chemoradiation therapy for resectable and borderline resectable pancreatic cancer. Ann Surg 258: 1040-1050, 2013.
3 Cavalieri E, Mariotto S, Fabrizi C, de Prati AC, Gottardo R, Leone S, Berra LV, Lauro GM, Ciampa AR and Suzuki H: alphaBisabolol, a nontoxic natural compound, strongly induces apoptosis in glioma cells. Biochem Biophys Res Commun 315: 589-594, 2004.

4 Costarelli L, Malavolta M, Giacconi R, Cipriano C, Gasparini N, Tesei S, Pierpaoli S, Orlando F, Suzuki H, Perbellini L, Piacenza F, Emanuelli $\mathrm{M}$ and Mocchegiani E: In vivo effect of alpha-bisabolol, a nontoxic sesquiterpene alcohol, on the 
induction of spontaneous mammary tumors in HER-2/neu transgenic mice. Oncol Res 18: 409-418, 2010.

5 Cavalieri E, Rigo A, Bonifacio M, Carcereri de Prati A, Guardalben E, Bergamini C, Fato R, Pizzolo G, Suzuki H and Vinante F: Pro-apoptotic activity of alpha-bisabolol in preclinical models of primary human acute leukemia cells. J Transl Med 9: 45, 2011.

6 Darra E, Abdel-Azeim S, Manara A, Shoji K, Marechal JD, Mariotto S, Cavalieri E, Perbellini L, Pizza C, Perahia D, Crimi $\mathrm{M}$ and Suzuki H: Insight into the apoptosis-inducing action of alpha-bisabolol towards malignant tumor cells: involvement of lipid rafts and Bid. Arch Biochem Biophys 476: 113-123, 2008.

7 Seki T, Kokuryo T, Yokoyama Y, Suzuki H, Itatsu K, Nakagawa A, Mizutani T, Miyake T, Uno M, Yamauchi K and Nagino M: Antitumor effects of alpha-bisabolol against pancreatic cancer. Cancer Sci 102: 2199-2205, 2011.

8 Uno M, Kokuryo T, Yokoyama Y, Senga T and Nagino M: $\alpha$ Bisabolol Inhibits invasiveness and motility in pancreatic cancer through KISS1R activation. Anticancer Res 36: 583-589, 2016.

9 Agazie Y, Ischenko I and Hayman M: Concomitant activation of the PI3K-AKT and the RAS-ERK signaling pathways is essential for transformation by the V-SEA tyrosine kinase oncogene. Oncogene 21: 697-707, 2002.

10 Hamacher R, Schmid RM, Saur D and Schneider G: Apoptotic pathways in pancreatic ductal adenocarcinoma. Mol Cancer 7: 64, 2008.

11 Sridharan V, Ruiz M and Menendez JC: Mild and high-yielding synthesis of $\beta$-keto esters and $\beta$-ketoamides. Synthesis 6 : 1053 $1057,2010$.

12 Cavalieri E, Bergamini C, Mariotto S, Leoni S, Perbellini L, Darra E, Suzuki H, Fato R and Lenaz G: Involvement of mitochondrial permeability transition pore opening in alphabisabolol induced apoptosis. FEBS J 276: 3990-4000, 2009.
13 Elmore S: Apoptosis: a review of programmed cell death. Toxicol Pathol 35: 495-516, 2007.

14 Fink SL and Cookson BT: Apoptosis, pyroptosis, and necrosis: mechanistic description of dead and dying eukaryotic cells. Infect Immun 73: 1907-1916, 2005.

15 Chen W, Hou J, Yin Y, Jang J, Zheng Z, Fan H and Zou G: $\alpha-$ Bisabolol induces dose- and time-dependent apoptosis in HepG2 cells via a FAS- and mitochondrial-related pathway, involves p53 and NFkappaB. Biochem Pharmacol 80: 247-254, 2010.

16 Patel VA, Longacre A, Hsiao K, Fan H, Meng F, Mitchell JE, Rauch J, Ucker DS and Levine JS: Apoptotic cells, at all stages of the death process, trigger characteristic signaling events that are divergent from and dominant over those triggered by necrotic cells: Implications for the delayed clearance model of autoimmunity. J Biol Chem 281: 4663-4670, 2006.

17 Poon IK, Hulett MD and Parish CR: Molecular mechanisms of late apoptotic/necrotic cell clearance. Cell Death Differ 17: 381397, 2010.

18 Schlieman MG, Fahy BN, Ramsamooj R, Beckett L and Bold RJ: Incidence, mechanism and prognostic value of activated AKT in pancreas cancer. Br J Cancer 89: 2110-2115, 2003.
Received November 24, 2016

Revised December 25, 2016

Accepted January 9, 2017 